\title{
Sustaining the old world, or imagining a new one? The transformative literacies of the climate strikes
}

\author{
Benjamin Bowman ${ }^{1 \rtimes \star(1)}$ and Chloé Germaine ${ }^{2}$ \\ ${ }^{1}$ Sociology, Manchester Metropolitan University, Manchester, UK and ${ }^{2}$ English, Manchester Metropolitan University, \\ Manchester, UK \\ ${ }^{\star}$ Corresponding author. E-mail: b.bowman@mmu.ac.uk
}

(Received 23 November 2020; revised 14 January 2022; accepted 14 January 2022; first published online 18 February 2022)

\begin{abstract}
In this article, we consider the climate strikes in the context of intergenerational narratives that de/limit young people's political subjectivities and imaginaries concerning climate change. Considering the strikes alongside other youth-led responses to the crisis, we reconsider the question of young people's climate change 'literacy' and posit that young people's literacies are characteristically transformative. Despite their broadly transformative nature, however, the climate change literacies of young people remain bound up in a complex, adult-centred discursive framework that limits young people in various ways, including positioning them as objects of care or otherwise objectivising their activism. We advocate interdisciplinary thinking in support of creative and transformative pedagogies arising from and informed by the climate strikes, arguing that young people's political subjectivities are indivisible from their cultural imaginaries. We advocate a step change in the way educators respond to the educational dimensions of climate strikes, as well as the educational opportunities this movement provides. Vitally, we include young people themselves in the category of educators and consider the ways the climate strikes represent an educational opportunity in which young people share, support and collaborate as educators and learners.
\end{abstract}

Keywords: civic education; climate change; creativity; environmental education; literacy; narrative; youth

\section{Introduction: From Deficit to Transformation}

'From the minute we are tossed into preschool we are told, Be quiet, raise your hand if you want to speak, listen to authority always, put your head down and do your work, and never question anything you are told. Memorize information and regurgitate it back onto a piece of paper. We are told, If you follow the rules, there is a safe and clear path ahead of you: get good grades and you'll be successful. Study hard for a bright future.' (Margolin, 2020: xiii. Emphasis in original.)

Jamie Margolin, author of Youth to Power (2020), activist and co-founder of the youth climate organisation Zero Hour, describes education as an interaction between the young person as a marginalised person and the adult as an empowered person in which the future is a contested concept. Margolin imitates the educator's voice - 'study hard for a bright future'-in the context of a global movement of young people's environmental activism that is mobilised, in part, by the warnings of scientists across the world that not only does the future look bleak, but it is possible that, without adequate action on climate change, there is no future for human civilisation as we know it 
(Hagedorn et al., 2019). A bleak future, or no future at all, is a challenge to any education that insists learners follow the rules. For young environmental activists, such as participants in the global Fridays for Future climate strike movement, it is time to pose the question: if being quiet and following the rules got us into this mess, why not get loud and break some?

In this article, we reflect on young dissent, specifically in the context of the climate strike movement led by young people seeking both action on climate change and social justice. We argue that while the climate strike movement is typically analysed as a protest movement, conceptually speaking, the movement is also a collaborative, youth-led endeavour in climate education. We consider young people's direct political action alongside youth-authored cultural texts as an educational process in which young people co-construct and navigate transformative literacies. Our concept of transformative literacies draws on international political definitions that hold literacy as a fundamental human right and a condition for individuals to participate in the 'effective functioning' of their community (UNESCO Institute for Statistics, 2008, p. 18). Building on this idea, transformative literacies aim at transforming communities rather than sustaining them. The work of transformative literacy includes improving conditions to widen participation in making change happen by fostering solidarity among and between communities. As we argue, this is precisely the work of the climate strike movement. The idea of transformative literacy also draws on what Knoblauch (1990) describes as 'critical literacy', a concept derived from academic circles that holds literacy as a process of inculcating consciousness of social conditions and of developing understanding of the ways in which language practices objectify and rationalise those social conditions. Such critical literacy is, for Knoblauch, 'a way to seek political enfranchisement' (1990: 79). This definition informs our concept of transformative literacy because young people are seeking enfranchisment through their strike action, but we hold that young people's climate action is not only aimed at critique; it performs a practical intervention that upends the structures of the very systems in which young people are embedded, particularly education-as Margolin's words suggest. These strikes are more than a protest. Young people, through the strike movement and its broader social and cultural context, do not simply call on adults to modify policy with adjustments like carbon emissions controls. They are engaged in imagining a better kind of society, developing the means to share and support each other, and authoring strategies for young and youth-centred action in a world that marginalises young people. We argue that the climate strikes as a movement represent a youth-led process of transformative education, because, through the manifestations of the movement, we argue that young people explore their visions of a future that is otherwise to the present. Their visions are different to the jarring and distrusted promises of a bright future that tend to be offered through traditional modes of civic education. Instead, young people explore visions of the future through transformative literacies that emphasise changing the world-radically, kindly and with care for others.

This paper is a theoretical reflection on the educational opportunities of the climate strike movement from a particular interdisciplinary perspective that explores the entwinement of young people's politics and young people's culture. Our disciplines are the study of young people's politics on the one hand and of young people's culture and literature on the other. We acknowledge that this perspective offers a different view from those that hail from within environmental education, and within education research more broadly, and offer the concept of 'transformative literacy' as a product of our specific disciplinary expertise. We begin by outlining the way in which we conceptualise literacy in the context of the climate strikes. We then consider how the climate strikes pose a particular challenge to notions of civic education. Moving from the political to the cultural, we show how these dimensions are intertwined in young people's responses to the climate crisis, and we examine the ways in which narratives authored by young people disrupt the discursive frameworks through which their activism is often mediated in the public sphere. This movement from civic action (the strikes) to creative texts suggests not the separation of these domains, but their entwinement. From here, our investigation is informed by approaches in literary studies to the climate crisis, which hold that creative texts make important interventions. 
These literary approaches emphasise the ways in which young people's transformative literacies foster openness, multiplicity and polyvocality-dispositions that will better help us confront the crisis. Finally, we reflect on ways educators might recognise the entwinement of creativity, subjectivity and political agency, and work with young people to further navigate and produce the multiple and transformative literacies already emerging in their grassroots action, public writing and cultural production on the climate crisis.

\section{On Transformative Literacies and Direct Action}

Our work builds on the turn away from deficit models of literacy in research on youth education from the past two decades and on work that calls for democratic approaches to developing education with young people. Morrell (2006) calls for researchers to treat young people as knowers about their own literacies and seekers of knowledge not tethered to pre-existing frames of deficit. Morrell argues that researchers should learn with and from youth cultures, recognising young people's assets and abilities. This approach responds to the negative identification and framing of adolescent literacies, especially in educational policy documents and in public perceptions. Likewise aiming at these negative perceptions, Vasudevan and Campano (2009) propose a conceptualisation of adolescent literacies built on sociocultural perspectives, that is recognising the socio-cultural context of literacy development. This involves documenting examples of young people taking up reading, writing, speaking and other modes of communication and expression that are 'intimately tied to their understandings of themselves in relationship to the world' (Vasudevan \& Campano, 2009, p. 312). We acknowledge these arguments and add to the conceptualisation of youth literacies the idea of 'situated knowledge' (Haraway, 1988). The notion of situated knowledge was developed by Donna Haraway as a corrective to the truth claims of scientific objectivity and to account for the contingency of knowledge claims and the precarious situations of knowing subjects.

Our argument, when it comes to situated knowledge and young people's literacies on climate change, is not that young people's knowledge is at odds with objective science and the knowledge, data and analysis of natural scientists. Rather, we argue that the knowledge of young people coexists with this information and is also important. If climate science is dominated by 'top down' (Tanner, 2010, p. 340) flows of knowledge, then we argue for a renewed interest in, and support for, a flow of knowledge from young people too. We agree with the international letter by leading climate scientists that called for recognition that young people are justified in their claims and their action (Hagedorn et al., 2019). Young people develop their knowledge and knowledge-making practices in specific contexts, these practices are embodied, partial, collaborative and accountable to their situation. The marginalisation of young people from institutions of power, for example, is one aspect of their situation that is recognised by youth activists as both a barrier and an opportunity. Reflecting on the political writing she published at age fourteen, for example, Jamie Margolin notes that she had a unique and important perspective on events, and she urges readers to likewise draw on the 'fresh energy, insight and unique power' they wield as young people (2020, p. 35).

This paper acknowledges that there is already a pre-existing commitment to working with young people in democratic ways in the field of environmental education (Rousell \& CutterMackenzie-Knowles, 2020), and that key principles of environmental education encourage participation in learning, active approaches to education, and the development of critical thinking (Palmer, 1998, pp. 10-11). Our intervention in this paper is to advocate for methods of working with young people that recognise action and writing by them as acts of climate change education, that recognise the climate strikes as a site where skills in participation, literacy and critical thinking are being developed by young people outside institutional structures. The school strike is a tactic of direct action that intervenes in education, in politics, and in the reproduction of the socioeconomic and political system. It disrupts daily life and challenges hegemonic narratives that imagine the future as continuous with the present, maintaining existing social structures and 
hierarchies. Critically, the school strike ruptures the traditional civic position of the young person, and especially the transition of young people to citizenship through education that serves as 'means for connecting young people to the political system, helping them to make sense of a complex political world, and thereby strengthening democracy' (Kisby \& Sloam, 2014, p. 52). The school strike is a tactic for young people to go beyond merely connecting to the political system: they want to transform it. Accordingly, our approach draws on our interdisciplinary expertise in politics, youth literature and cultural studies to better understand the ways in which the climate strikes intervene not only in civic life, but also in wider cultural and social narratives that would otherwise constrain young peoples' actions and imaginaries. Our work thus responds to problems in both the study of youth literature and culture, and in the study of youth politics. Studies of youth literature ignore young people and their lived realities, focussing instead on the contents of texts. There is also a relative paucity of methods for considering young people's lived worlds as political arenas, not just as cultural ones (Kallio \& Häkli, 2011a). The interdisciplinary, explorative principles developed at the end of this paper bring together concepts of creative expression, youth literature and youth politics so that educators and other adults can support young people's imaginings of the future, not just as self-expression nor as a simple articulation of policy requirements, but as a mixture of the two. Our aim, then, is to build theory from young people's visions of social, economic and political change in response to the climate emergency.

We, the authors, are grateful of the opportunity to contribute to this interdisciplinary special issue of the Australian Journal of Environmental Education from our disciplines outside education. We hope that our work can support educators and educationalists, as well as those of us outside the discipline of education, to respond to Rousell and Cutter-Mackenzie-Knowles's challenge 'to be daring enough to research beyond redundant investigations interrogating children and young people's knowledge of climate change science' and 'towards working directly with children and young people themselves in genuinely collaborative, imaginative and creative ways through the emerging transdisciplinary field of climate change education' (2020, p. 203). While we remain humble about the limits of our ability to inform educationalists in the specialities of their own discipline, as transdisciplinary scholars, we hope that educationalists who consider that 'climate change education finds its purpose in cultivating climate action' (Verlie, 2017, p. 562) will be supported by our contributions on climate action; we hope that educationalists who argue that education tends to be about the changing climate, but that 'education in the changing climate is rarely advocated or explored' (Verlie \& Blom, 2021, p.4) will find our contributions on youth-centred approaches helpful.

\section{The Climate Strike and Challenges to Notions of Civic Education}

The school strike is a form of civil disobedience by which young people, as a marginalised group in society, can claim democratic agency. School strikes have formed part of numerous cycles of contention throughout history. In the UK, for example, school strikes have been a part of the national fabric of political activism ranging from school walkouts in general alignment with nationwide workers' unrest in 1899 (Taylor, 1994), to strikes in solidarity with wider opposition to the 2003 invasion of Iraq (Cushion, 2007). As a familiar form of young activism, the school strike continues to offer young people a tactic for disrupting the education system. The UK Student Climate Network, a body of young people working to organise and support climate activism, offered the following suggested text as part of a draft letter for school pupils to send to school management, in order to request permission to strike:

'Active civic engagement is part of your duty as a citizen and playing an active role in society. Voting every four years is not the only part of the democratic process. Indeed, many of our members have no ability to vote, being too young; and have no say on the security of their own future' (UKSCN, 2020). 
Young people, as the UKSCN identify them, are members of society and are understood to have civic roles, rights and duties accordingly. Using the UKSCN's terminology, civic education is generally considered to be that which supports active civic engagement, informs and enables citizens in carrying out their duties, and empowers them to take an active role in society, of which one commonly identified role is that of the voter.

Phrases like 'active civic engagement', 'connecting (...) to the political system' and, particularly, the pivotal word 'engagement' speak to the historical condition of anxiety 'that young people are disengaged from politics and civil society, indeed from the entire public sphere' (Banaji, 2008, p. 543). It is hegemonic, to the point of becoming a form of common sense, that young people represent an 'incipient "crisis of democracy" (Farthing, 2010, p. 181) because, as Farthing explains, young people are almost always considered to be 'deficient' (2010, p. 183). The framing of young people having a duty to be active, and the concept of youth as a period of civic engagement - and engagement must be emphasised as the term on which this concept pivots-is a deficit model akin to that which has dominated in concepts of literacy. Practically speaking, in the context of climate education in a period of young environmentalist action, a deficit model of young people as civic actors leads to 'attempts to "fix" the deficit in young people through education' (Farthing, 2010, p. 183).

As a result, young protest, civil disobedience and direct action represent a challenge to civic education. As O'Brien, Selboe and Hayward write, civic education 'can be promoted and directed toward consent, cohesion and loyalty, rather than contestation and dissent' (2018, p. 5). Civic education, partly because the contemporary conceptual landscape is so dominated by the idea that young people are deficient civic actors, fulfils a vital role in empowering young people with the skills, tools and knowledge to understand key issues and to participate in the social and political systems of democracy. These two branches of education, however, are challenged by young people who dissent. Young people who dissent may feel institutional education does not provide the skills and knowledge they need, and they may not wish to sustain existing systems but change them. For this reason, young dissent is a challenge to the limitations of a dyadic model of civic education, formulated on a concept of young civic deficiency.

\section{The Dyadic Model of Civic Education and Its Limitations}

Mainstream concepts of civic education, then, consist of two strands. First, young people are considered to go through education as a process of acquiring the knowledge, tools, skills and grammars of participation that support them as civic actors. Second, education is conceptualised as a process of engagement, and specifically a 'pro-social and conformist' transition to citizenship (Banaji, 2008). Although civic education varies greatly from place to place and context to context, the kernel of civic education is transitional. Young people are considered to go through education as a transition from disengagement to engagement; this process of engagement, furthermore, is a process by which democracy itself is sustained. Young people, through civic education, renew democracy as voters, citizens and members of the public.

The dyad of civic education for young people is a dualistic transition to citizenship. Education brings young people into engagement with democracy and, in so doing, sustains democracy with each new generation of democracy citizens. Education also provides young people the tools with which to change democracy: to have a voice in society but also, vitally, to have power. The power of young people to change democracy is a challenge to the dyad of civic education. In their work on new civics, Haste, Bermudez and Carretero identify 'the inherent tension between the goal of creating citizens who will be actively involved in sustaining the existing socio-political system, and the goal of creating citizens who are equipped to challenge the status quo' (2017, p. 3 ).

We explore the dyadic model of civic education at length here because young climate activism-including the school strikes-must, frankly, drive climate educators to recognise 
and respond to its tensions. For young climate strikers, who so frequently call for 'Systems Change, Not Climate Change' (Gobby, 2020, p. 245) and whose activism employs 'different modes of dissent' (O’Brien, Selboe, \& Hayward, 2018), sustaining the existing socio-political system is not at all the goal of their activism, nor is mere engagement and participation in institutional democracy a sufficient tactic to achieve their goal of systemic change. A climate strike is a disruptive tactic, and young climate strikers are often not just protesters, but dissenters (Bowman, 2020; O'Brien et al., 2018), seeking quite literally to 'challenge the status quo' (Haste, Bermudez, \& Carretero, 2017, p. 3). Thus, the activism of young people who dissent is a challenge to climate education as it is a challenge to traditional civic education. This challenge is partly the familiar struggle of protesters to be recognised as 'agents of democracy, not pathological deviants' (Haste et al., 2017, p. 4) but it is not just about recognising direct action among young people who attend a protest. In the same way that new approaches to civic education consider it vital to 'broaden the definition of civic participation' (Carretero, Haste, \& Bermudez, 2015, p. 300), so too must educators broaden the scope of climate education in connection to the civic. This means recognising young activists, but also young non-activists whose politics may be shaped by everyday experience and whose participation may be issue-based, local and on a case-by-case basis (Sloam, 2020). It means recognising how young people have a voice, but also the politics of young 'voicelessness' (Kallio \& Häkli, 2011b) as young people adapt to and subvert their marginalisation from adult society; and the expanding grammars of participation among young people as 'everyday makers' (Bang, 2010) or 'Do-It-Ourselves' citizens (Pickard, 2019).

Young people are not monolithic, but it is generally the case that the politics of the young, including the grammars of political activity employed by the young, are characteristic. The broadening of the definition of civic participation is partly a process of accommodating young people into a broader range of civic participation, but it is also a process by which characteristically young modes of participation must be regarded as part of the civic realm rather than deviations from it. Young people do not need to do politics in a way that pushes adults to act; they do not need to have a voice in such a way that their demands are easily understandable and actionable (or ignorable) by adults in power. Their political subjectivities, sense of belonging and so forth, are no less valid if they do not align those subjectivities with dutiful electoral participation. Indeed, young civic participation includes processes of contestation, dissent and direct action that are not deficient but different, because they are youth-led and youth-centred. That young people can have different civic participation to older people without having deficient civic participation is a simple concept, but a challenging one, for both civic and climate education.

\section{Young Protest, Direct Action and Dissent}

As Nissen et al., write, the climate strike movement 'has brought children and young people's climate crisis activism into the public sphere in unprecedented and courageous ways, but it is also dissent that extends beyond these highly visible protest events' $(2020$, p. 5). For climate education, the broadened definition of civic participation, and the recognition of broader repertoires of political contention and dissent among young people, demand a reinvigorated interest in what the civic goals of climate education are to be. Young people's repertoires of political behaviour are broader, in part, because when they take political action, young people tend to be more ad hoc, more flexible and more informal in what they do than adults (Pickard, 2019). It is true that young people's politics can come across as informal to those of older generations. Nevertheless, even if young people seem informal in their action, we argue that the history of climate justice activism including among young people runs deep. The climate strike movement is characterised by a demand for climate and intergenerational justice (Bowman, 2020; Nissen, Wong, \& Carlton, 2020, p. 1). As such, the contemporary climate strike movement is situated within a longer historical tradition of activism, and especially environmental justice activism, that consider climate change and other 
environmental issues to intersect with the enduring social, political and economic inequality in a world shaped by colonialism and capitalism (Bowman, 2020; Curnow \& Helferty, 2018).

These characteristics of the contemporary politics of climate change, as it pertains to young people, require climate educators to recognise and uphold the tension between civic education as a tool that sustains existing socio-political systems and education that empowers citizens to challenge those systems. In climate education, that tension coincides with 'the continued dominance of top-down information flows' on climate change (Tanner, 2010, p. 340) as well as historical tendencies to 'frame the goals of the environmental movement in narrowly constructed, technocratic, and dehistoricized ways' (Curnow \& Helferty, 2018, p. 149) particularly among white, middle-class adults (Pulido, 1996, p. 25). While it is true that climate change is something of a divisive political topic, and climate education may be a way to 'tell the truth about the facts' (Boykoff \& Yulsman, 2013, p. 363), the climate strikes instruct educators that young people are developing literacies beyond simply learning about the climate crisis, communicating demands to adults, or understanding mainstream environmentalist policy demands. The climate strikes are profoundly complex sites of contestation, horizontalist democratic innovation and explorations of local and global solidarities including the contradictions of those solidarities (Gobby, 2020). Vitally, they are sites of direct action: places where young people are attempting to imagine a new world, not just ways to manipulate the politics of the current one. In the same way that the dominant sense of civic participation positions young people as deficient civic actors who need to be 'engaged' through educational 'fixes' (Farthing, 2010), a dominant cultural narrative positions them as subjects-in-process in need of guidance and socialisation.

In the next section, we consider this interplay of young people's civic participation and the cultural narratives that frame and mediate their participation. What could be called the civic nature, or the political components, of young people's self-expression remain underexplored, since existing academic literature tends to divide, in an unnecessary and limiting way, political instruments like institutional participation from expressive processes like every-day talk with friends (Bowman, 2019, p. 301). We contend that political motivations and expressive motivations are, for young people, enmeshed in one another, and that the permeable divide between the political and the personal offers significant opportunities for exploring the crossover between the civic and the cultural narratives and for unpacking the 'transformative literacies' of young people's action.

\section{How Young Climate Activism Negotiates and Challenges Discursive Constraints}

Although young action on the climate crisis in the forms we have discussed have received a great deal of public attention, it is often mediated through cultural narratives and discursive frames that interpolate young people in an intergenerational power relationship, objectivises them either as objects of care or as resources from which the future will be built, and locates them in a domestic sphere where their concerns are interpreted in light of their home lives and education. These narratives comprise a dominant 'literacy' in adult culture-a way of reading - that positions young people in paradoxical ways in relation to the climate crisis. This is a further sense in which our research interrogates the concept of literacy in relation to young people's action on the climate crisis, because we contend that adults must interrogate the ways in which they understand young people's response to the climate crisis.

In an article that typifies the more negative of these intergenerational narratives, UK newspaper columnists Sandbrook (2020) castigates parents for 'indulging' their 'self-righteous' children and failing to instil adult responsibility in their teenagers. The article is illustrated with photos from youth climate strikes in which young women feature prominently and Greta Thunberg is positioned as the 'crusader' par excellence. Sandbrook says nothing about the aims of the school strike movement, only that its instigator is 'quite literally a child' and so ought to be in school. This a particularly egregious example of popular news coverage of young peoples' action on the climate 
strike, but it reveals the discursive constraints that elsewhere operate albeit more implicitly. JohnsPutra $(2019$, pp. 4, 19) points out that environmental discourse is itself dominated by a 'parental rhetoric of posterity' that collapses a complex web of interspecies obligations into a single intergenerational lineage whereby the earth must be saved for future (human) generations-for children. Environmental posterity positions children as objects of care and moral patients rather than moral or political agents themselves. These ideas about young people owe much to the persistence of a Romantic ideology of childhood, deriving in large part from the seventeenth century writing of John Locke and Jean Jacques Rousseau, which positions children on the side of nature rather than as actors in a public and political sphere. The Romantic child is an as yet-incomplete subjects whose 'natural' inclinations need to be moulded so that they can become civic actors governed by reason. This is the basis of dominant readings of young people as activists as well as the origin of the notion of civic education discussed above.

The flipside of the Romantic construction that pervades popular narratives about young people is that the child is perceived to embody naturalness, innocence, imagination, immediacy, simplicity and other such qualities lacking in adulthood (Natov, 2003). This conception of naturechildhood frames much public and political discourse on the climate crisis. Climate change 'has made an always uncertain future even more unknowable' (Buckley, 2020). Primarily, the legacy of the association of the child with nature is that young people are positioned as guarantors of the unknowable and uncertain future of humanity. It is not only that news headlines such as 'The old made our climate mess. And the young will get us out of it' (Solnit, 2019) place the burden of change on those without the power to enact it, but that this burden is freighted with ideological baggage. As Taylor (2013, p. xii) notes the seemingly natural connection between children and nature has the status of a 'reassuring fact of life', and this reassurance permeates narratives of climate crisis. Goga, Guanio-Uluru, Oddrun Hallås, and Nyrnes (2018, p. 1) suggest that Rousseau's romantic view of children and nature frames political discourse and action, connecting children to the idea of restoring a threatening environment. Alice Curry likewise notes the association of children with green shoots, buds and flowers in contemporary fiction, which operate as a metaphor for 'earthly restoration' (2013, p. 32). These understandings of children and young people in relation to the climate crisis operate as a double bind, constraining not only their actions and how those actions are represented and perceived, but also threatening young people's emerging competencies as agentic subjects. These dominant literacies, or readings of, youth and the climate crisis restrict young people to the domestic sphere, positioning them as subjects-in-process in need of guidance and socialisation, on the one hand, while objectivising them on the other hand as resources of restoration, framed by a nostalgic understanding of the nature that has been 'lost'. This rhetoric is often paradoxical as children and young people are simultaneously held to be losing contact with nature due to their technological lifestyles and lack of interest in nature. However, in a recent study Novotny, Zimová, Mazouchová, and Šorgo (2020) contend that young people's experience with nature is not decreasing, merely changing in context. As discussed above, the issue for educators to comprehend is that this is a different context for young people's lived experiences, rather than a deficient one.

Dominant understandings of young people in relation to the climate crisis are often nostalgic, then, constructing young people in relation to a lost past that might be restored. Such constructions associate young people with a certainty that is precisely what the climate crisis disrupts, especially for young people for whom the future has never been more uncertain. Curry's work on the figure of the adolescent in fiction points to Octavia Butler's dystopian novel The Parable of the Sower (1993) as expressing this paradoxical yet pervasive idea. In the novel, a young protagonist notes that the adults are 'still anchored in the past, waiting for the good old days to come back. But things have changed a lot, and they'll change more (...) People have changed the climate of the world. Now they're waiting for the old days to come back' (Butler quoted in Curry, 2013 , p. 5). The climate strikes have, of course, made it clear that young people have no interest in the 'old days'. Johns-Putra likewise identifies a grasping at certainty in environmental discourse 
that uses the comforting frame of parenthood and posterity $(2019, \mathrm{p}$. 7$)$. The child becomes a convenient signifier for a knowable future in such discourse, but the future is exactly what is not knowable - as Margolin attests when she rejects traditional models of education, asking 'what happens when there is no future to study for?' (2020, p. xiii). Not only do we need more radical possibilities for a future-oriented ethics, as Johns-Putra suggests, we also need better ways of understanding - that is, better literacies - that can process this profound uncertainty. As Hamilton (2017, pp. 26-27) has argued the 'rupture' of the Anthropocene has no analogue in history and the idea that ecosystems can bounce back or be restored are nonsensical in the face of catastrophic geological-scale changes and the resultant climate tipping points. Echoing JohnsPutra and Hamilton, Roman Bartosch suggests that any literary pedagogy, that is one that would seek to learn with and through cultural and literary texts, must build our capabilities of 'being in uncertainties' Bartosch (2019, p. 4).

Young people are alert to this uncertainty in the narratives they produce, whether these are literary narratives, as publishers begin to take an interest in works by young activists, or else the ephemeral narratives and images that emerge through the climate strikes themselves. Young people's responses often articulate this sense of a profound and completely novel catastrophe in ways that the dominant narratives of the climate crisis and young people's action have not yet grasped. For one thing, the school strikers' cry of 'System Change Not Climate Change' starkly refuses any move to restore a lost world, or to go backwards. Margolin's opening salvo in Youth to Power also demonstrates the refusal of youth activists to cleave to comforting narrative frames or certainties. Margolin notes that none of the old rules apply and the safe and clear path to a successful future preached by parents and teachers is no longer available in 'a climate-changewarped world where we are guaranteed no tomorrow' (2020, pp. xiii-xiv). Rather than taking up the subject position of guarantors of restoration or of a certain future, then, young climate activists turn the dominant narratives back onto adults in power. This is a rhetorical strategy often deployed by Greta Thunberg, exemplified in her 2019 Stockholm speech, 'I'm too young to do this'. She tells her audience that 'saying everything will be all right while continuing to do nothing at all is just not hopeful to us (...) You can't just sit around waiting for hope to comeyou're acting like spoiled, irresponsible children' (2019, p. 40). Note how Thunberg here turns the rhetoric used to limit and silence youth activists, seen in the Sandbrook article quoted above, back onto those with the power to act at a legislative level but who have so far refused to do so. Young activists thus acknowledge uncertainty in their own developing literacies and rhetorical strategies, and, from this position, challenge the intergenerational narrative frames imposed by adult culture.

\section{Transformative Literacies: Negotiating Uncertainty, Hope, Anxiety and Solidarity}

The school climate strike movement challenges the boundaries of the civic and practices of climate education. The movement challenges hegemonic narratives about childhood and youth, and the traditional boundaries that limit young people's subjectivities. The climate strikes also challenge dominant conceptual understandings of what comprises young political agency and how it is manifest. In this section, we respond to these challenges by exploring examples of transformative literacies, focusing on texts produced by young people who are prominent figures in a public conversation about the climate crisis. Our main contention in this analysis is that young people's sense of political agency is bound up with their subjectivity and, as such, indivisible from, and developed through, their creative self-expression. Through this analysis we also illustrate the transformative literacies demonstrated by young people through their creative and public writing on the climate crisis.

Dara McAnulty's Diary of a Young Naturalist, written by the teenage author, exemplifies this mutually constitutive relationship of subjectivity and political agency and demonstrates one of the 
ways in which young people are developing new narratives and literacies that challenge the bifurcation of the personal and the political and, as such, their marginalisation. McAnulty's book is an example of nature writing, comprising edited diary entries that trace his experiences with his local environment. The book also advocates for the conservation of this environment and describes the ways in which habitats are being transformed by the changing climate. His narrative is intensely personal and explicitly political. One entry describes hie encounter with a male corncrake desperately keening for a mate in the bleak agricultural landscape, which has all but destroyed the birds' habitat. McAnulty writes, 'I feel such loneliness and despair watching it, listening in. A surge moves through me. I have to do something. I have to speak out. Rise up' McAnulty (2020, p. 50). The creative narration of this encounter enfolds the writer's emotions and the political agency that emerge in the same moment. These emotions are not hopeful, rather they mingle anxiety with grief and anger. Through the expression of negative emotions, McAnulty develops a different mode of resistance to the objectivisation of young people as guarantors of renewal to that expressed in Thunberg's speeches. McAnulty's narrative points to ways in which creativity, self-expression and political action coalesce in a desire for change. He tells the reader, 'I have the heart of a naturalist, the head of a would-be scientist, and the bones of someone who is already wearied by the apathy and destruction wielded against the natural world' $(2020, \mathrm{p}$. 7$)$. His is a complex literacy that eschews the deficit model and the functional competencies imposed on him by the school curricula. He wryly notes the book is a particular achievement given that teachers told his parents, 'your son will never be able to complete a comprehension, never mind string a paragraph together' $(2020$, p. 9). In a striking rebuke to the pessimism of McAnulty's teachers, his book won the prestigious Wainwright Prize for UK Nature Writing shortly after publication, the first book authored by a young person to do so. The transformations McAnulty explores in his writing, then, pertain not only to imagining better relationships between people and the environments in which they are embedded, a key aim for environmental education, but also of an education system that has excluded and marginalised his voice.

McAnulty's work is not the only example of creative youth activism making an impact in a broader cultural imaginary around rights for nature and action on the climate crisis. Jamie Margolin's handbook written for youth activists, already discussed, is not only an instruction manual for grassroots organising, but an exploration of the development of her own political subjectivity. She begins by urging readers to find their why, the something that they are fighting for that they cannot live without (2020, p. 4). Like McAnulty, her environmental activism emerges from her connectedness to a specific environment, from her love of the mountains and hills of the Pacific Northwest. Her activism is also grounded in her experience as a lesbian living in a heteronormative society. She notes that she has experienced 'shame, stress, depression, alienation and anxiety' and is explicit about her activism being 'rooted in my identity and personal lived experiences' (2020, p. 5). Here, as in McAnulty's writing, hopefulness about how young people's actions can positively transform the future is mingled with acceptance of its uncertainty and with the negative emotions Margolin experiences as a marginalised young person and an LGBTQ + climate activist. Here, again, the aim is not only to enable participation by providing young people with the critical, practical and political skills they need to contact their representatives, set up petitions, and write for the media - though the handbook does offer all those things. Margolin also aims at a bottom-up transformation of society by reaching out in solidarity to other young people who have also experience the alienation and anxiety she describes.

Youth activists express themselves creatively in a range of media. Xiuhtezcatl Roske-Martinez, director of the conservation organisation Earth Guardians, is a musician. His early eco-hip-hop tracks 'What the Frack' and 'Speak for the Trees' (2014) aim to communicate ecological issues specific to his home state of Colorado in the United States. At the start of 'Speak for the Trees', Roske-Martinez draws on the more traditional environmental posterity narrative discussed above, asking the listener to consider ' $[w]$ hat will be left for my generation at the end of the day' if the plunder of forests continues unabated. However, as the song develops, the singer shifts 
position. He moves from identifying as a protector of the trees, drawing comparisons with the American children's book character invented by Dr Seuss-The Lorax, to speaking as the trees themselves, including the listener in this biocentric rhetorical strategy:

'Your body is a tree like gardenia

Your heart is the seed and it beats for love!

You are the Baobab, Redwood, \& Pine:

You are the future in present time.' (Martinez et al., 2014)

This shift from a narrative of posterity to a biocentric image of the self as a tree includes all listeners regardless of their age and dissolves the intergenerational divide implied by the earlier question-'what will be left for my generation'? The shift to speaking as a tree also draws focus away from a posterity narrative that objectivises children and nature as objects to be protected and locates, instead, the potential for a new future in the present time. This potential emerges from the engagement of the activist - and here the 'you' addresses both young and old listeners - with the land itself. This engagement is not merely instrumental, in which trees are a resource to be protected for the future, but creative, imagining an entanglement between self and tree as the starting point for action in the present. The transformation imagined in the song also aims at fostering intergenerational solidarity that reaches into the future, too.

In her short video, 'Imagine the Future', indigenous youth climate activist from Mexico, Xiye Bastida also advocates for the imagination to solve the climate crisis and combat feelings of despair. The video combines footage of her speaking directly to camera interspersed with different images, including forms of energy efficient public transport, sources of renewable energy, organic farms and city residences covered in green foliage and gardens. Bastida (2020) suggests that a future otherwise to the present is possible if only we dare to imagine it. 'This is what your city looks like', she suggests as she moves the viewer into this future time, with 'food growing on rooftops' and the 'city as a sanctuary for nature and wildlife.' Here, the transformative literacy being developed in the context of the climate strikes manifests as an exhortation to viewers to challenge their conceptions of the future that are rooted in the present. 'Are you really picturing it?' Bastida repeats insistently. Crucially, the video is offered as a viral message that viewers are encouraged to share to 'help those around you have the courage to imagine it too'. This is another hopeful and creative intervention in the climate crisis that is about advocating for the power of the imagination in a way that breaks down intergenerational divides and conflicts. In its insistence that viewers imagine together, the video engages us in a moment of intergenerational solidarity to make possible a future without recourse to nostalgia, nor any other form of intergenerational discourse that would objectivise or marginalise young people.

Each of these interventions demonstrate the transformative literacies being developed by young people in response to the climate crisis. The interventions go well beyond the traditional limits of civic engagement and climate education, challenging the discursive constraints perpetuated by hegemonic narratives about young people and the climate crisis that would otherwise limit young people's subject positions. Crucially, these texts authored by young people demonstrate that the creative expression of their subjectivity is indivisible from their political contexts and from the lived experiences from which they write and create.

\section{Reflecting on and Responding to Young People's Transformative Literacies}

In this final section of our paper, we reflect on how to respect and respond to the transformative literacies of young people, whether these young people self-identify as climate activists or not. Young people frequently resist terms like 'activist' and 'politics', which may or may not speak 
to them as an effective descriptor for what they are doing. Young people's activism may feel, to them, nebulous rather than fixed, and resistant to formal categorisation as 'political'. At the same time, adults - including adults who express support for young environmentalism - so frequently use the conceptual boundaries of activism and of the political to define what young people do as deficient, in need of a fix, or not counting as proper politics, that we consider the imposition of terms like 'activist' and 'politics' problematic. Some young people will resist the term 'activist' to better claim agency over their civic activity, in defiance of adult centred concepts of activism. We remain open to youth-centred capacities, literacies, terminology and frameworks.

Cultivating openness towards the capacities and literacies young people are developing outside classrooms will also allow educators to work with young people to challenge some of the discursive constraints around their agency and participation in political and social life, and to identify creative and cultural resources that young people can draw on in the development of their political subjectivities. This involves working with process-over-outcome frameworks where no deficit is assumed on the part of young participants. Examples of such work can be found in participatory research projects, such as Justyna Deszcz-Tryhubczak's Child-Act (2019). Deszcz-Tryhubczak (2019) suggests that researchers interested in children's culture and literature, for example, need to 'catch up with Thunberg and her peers by developing new practices of thinking and doing our research that both reflect children and adult's joint vulnerability and affirm the possibility of shared agency in the face of earth's finitude' Thunberg (2019, p. 186). Her proposal for intergenerational collaboration positions primary-school-age children as active contributors to all elements of the research process. Deszcz-Tryhubczak introduced the children's book, Un-Lun-Dun by Miéville (2007) to two focus groups comprised of primary-school-age children (aged 11) in the UK. This was not a teaching and learning activity in the traditional sense but worked with the children to generate creative outcomes on the theme of the climate crisis, which were different in each group. This shift away from an outcome-centred approach that seeks to use the text in a particular way or derive from its reading a particular skill or understanding, which is the norm in classrooms, is one approach to responding to and supporting transformative literacies.

We also find inspiration for our reflections in new work on literature, pedagogy and the climate crisis. This synthesis recognises the fact that the political and the creative are mutually constitutive dimensions, particularly for young people. Roman Bartosch is one of the researchers advocating for the use of literary texts in an educational context to confront the climate crisis. His literary pedagogy argues for the 'importance of learning about the earth's natural-cultural worlds through reading and engaging with narratives' $(2019$, p. 3). Bartosch contends that reading literature can foster the 'perspectival and epistemological flexibility' that is required in the face of the climate crisis, a flexibility on the part of the reader that encounters alterity and fragmented or multiple perspectives $(2019$, p. 6). Finally, his pedagogy seeks to overturn dominant models of reading in education, which suggest readers learn from texts, with the proposal that readers learn through texts $(2019$, p. 9). As we have suggested, this flexibility is already being developed by young people through their engagement with the climate strikes and in their creative responses to the crisis. Young people's climate literacies already engage with diverse stories, narrative modes and cultural images in a range of ways that demonstrates the pedagogical approach developed by Bartosch: they are learning through texts, and by making their own texts, often outside formal educational settings. Bringing the expertise and experience of young people to bear on these new literary pedagogies will allow those working in literary studies to learn from the insights of young people already active in responding to the climate crisis, and who are frequently represented by adults in literary and cultural texts but rarely get to speak back to those representations.

Participatory methods build a concept of the political by working with young people rather than employing adult-centric frames of reference like engagement and participation. We need to follow suit in developing techniques that enable young people to be co-researchers across literature, culture and politics, and climate education, building their capacities as readers and writers and giving them a stake in the outcomes both within and without traditional educational settings. 
Certainly, young people are aware that the old promises of education no longer ring true so new outcomes will need to be formulated in collaboration with young people themselves.

We suggest the following actionable principles we consider we must take ourselves, and we hope that they will be helpful in consideration by educators and others seeking to work with young people on the climate crisis:

- Recognise the competencies young people bring to your activity/setting.

- Uphold the contradictions of solidarity (Curnow \& Helferty, 2018) in young people's environmentalism: the impacts of climate change are unjust at all levels from the local to the global.

- Make space for young people to define what they do for themselves. Let them use their own terms, their own language, and their own ways to describe what they do.

- Respond to the discursive frameworks and existing narratives about young people that already circulate and mediate their relationship to the climate crisis.

- Respect the multiplicity of youth literacies.

- Work with the situated knowledge held and enacted by young people, which includes their socio-geographical-racial-cultural locations but also any self-identified elements.

- Develop frameworks and outcomes with young people rather than imposing them from the outset.

- Embrace uncertainty and ambiguity about the climate crisis and the future.

- Create space for negotiating both positive and negative emotions.

- Recognise or represent, where appropriate, the notable leadership of young women.

Going forward we hope to implement these principles in our research with young people and refine our conceptual approaches to the climate crisis in collaboration with young people as co-researchers. We are cognisant of the challenges involved in this work and our future research will be aimed at better understanding such challenges. The transformative literacies young people are developing in their responses to the climate crisis have much to teach adult educators and researchers about better ways to support and work with young people, in all their diversity, as they navigate the uncertain future to come.

Acknowledgements. None.

Conflicts of Interest. None.

Financial Support. This research received no specific grant from any funding agency, commercial, or not-for-profit sectors.

\section{References}

Banaji, S. (2008). The trouble with civic: A snapshot of young people's civic and political engagements in twenty-first century democracies. Journal of Youth Studies, 11(5), 543-561.

Bang, H. (2010). Everyday makers and expert citizens: Active participants in the search for a new governance. In J. Fenwick and J. McMillan (eds.) Public management in the postmodern era: Challenges and prospects (pp. 163-191). Cheltenham: Edward Elgar.

Bartosch, R. (2019). Literature, pedagogy, and climate change. Cham, Switzerland: Palgrave Macmillan.

Bastida, X. (2020). Imagine the future with Xiye Bastida. Retrieved November 19, 2020 from: https://www.youtube.com/ watch? $\mathrm{v}=\mathrm{GBeU} 6 \mathrm{UZyPjY}$.

Bowman, B. (2019). Imagining future worlds alongside young climate activists: A new framework for research. Fennia: International Journal of Geography, 197(2), 295-305.

Bowman, B. (2020). 'They don't quite understand the importance of what we're doing today': The young people's climate strikes as subaltern activism. Sustainable Earth, 3(16), 339.

Boykoff, M.T., \& Yulsman, T. (2013). Political economy, media, and climate change: Sinews of modern life: Political economy, media, and climate change. Wiley Interdisciplinary Reviews: Climate Change, 4(5), 359-371. 
Buckley, C.G. (2020). Climate change and the contemporary novel by Adeline Johns-Putra. C21 Literature: Journal of 21st-Century Writings, 8(1), 1-6.

Carretero, M., Haste, H., \& Bermudez, A. (2015). Civic education. In E.M. Anderman \& L. Como (Eds.), Handbook of educational psychology (pp. 295-308). London: Routledge.

Curnow, J., \& Helferty, A. (2018). Contradictions of solidarity. Environment and Society, 9(1), 145-163.

Curry, A. (2013). Environmental crisis in young adult fiction: A poetics of earth. Basingstoke: Palgrave Macmillan.

Cushion, S. (2007). Protesting their apathy? An analysis of British press coverage of young anti-Iraq war protestors. Journal of Youth Studies, 10(4), 419-437.

Deszcz-Tryhubczak, J. (2019). Thinking with deconstruction: Book-adult-child events in children's literature research. Oxford Literary Review, 41(2), 185-201.

Farthing, R. (2010). The politics of youthful antipolitics: Representing the 'issue' of youth participation in politics. Journal of Youth Studies, 13(2), 181-195.

Gobby, J. (2020). Climate justice Montreal: Who we are and what we do. In P.E. Perkins (Eds.), Local activism for global climate justice: The great lakes watershed (pp. 234-245). Abingdon: Routledge.

Goga, N., Guanio-Uluru, L., Oddrun Hallås, B., \& Nyrnes, A. (2018). Ecocritical perspectives on children's texts and cultures: Nordic dialogues. London: Palgrave Macmillan.

Hagedorn, G., Kalmus, P., Mann, M., Vicca, S., Van den Berge, J., van Ypersele, J.-P., .. Hayhoe, K. (2019). Concerns of young protesters are justified. Science, 364(6436), 139-140. DOI 10.1126/science.aax3807.

Hamilton, C. (2017). Defiant earth. The fate of humans in the anthropocene. Crows Nest, Australia: Allen and Unwin.

Haraway, D. (1988). Situated knowledges: The science question in feminism and the privilege of partial perspective. Feminist Studies, 14(3), 575-599.

Haste, H., Bermudez, A., \& Carretero, M. (2017). Culture and civic competence: widening the scope of the civic domain. In B. García-Cabrero \& A. Sandoval-Hernández (Eds.), Civics and citizenship: Theoretical models and experiences in Latin America (pp. 3-16). Rotterdam: Sense.

Johns-Putra, A. (2019). Climate change and the contemporary novel. Cambridge: Cambridge University Press.

Kallio, K.P., \& Häkli, J. (2011a). Are there politics in childhood? Space \& Polity, 15(1), 21-34.

Kallio, K.P., \& Häkli, J. (2011b). Young people's voiceless politics in the struggle over urban space. GeoJournal, 76(1), 63-75.

Kisby, B., \& Sloam, J. (2014). Promoting youth participation in democracy: The role of higher education. In A. Mycock \& J. Tonge (Eds.), Beyond the youth citizenship commission: Young people and politics (pp. 52-56). London: Political Studies Association.

Knoblauch, C.H. (1990). Literacy and the politics of education. In A.A. Lumsford, H. Moglen \& J. Slevin (Eds.), The right to literacy (pp. 74-80). New York: The Modern Language Association of America.

Margolin, J. (2020). Youth to power. Your voice and how to use it. New York: Hachette.

Martinez, X., Martinez, I., Caress, I., Martinez, T., \& Meador, J. (2014). Speak for the trees. Retrieved November 19, 2020 from https://unfccc.int/news/8-july-2015-this-week-climate-song-for-paris-cop21

McAnulty, D. (2020). Diary of a young naturalist. Dorset: Little Toller Books.

Morrell, E. (2006). Critical participatory action research and the literacy achievement of ethnic minority groups. National Reading Conference Yearbook, 55, 1-18.

Natov, R. (2003). The poetics of childhood. New York: Routledge.

Nissen, S., Wong, J.H.K., \& Carlton, S. (2020). Children and young people's climate crisis activism - a perspective on longterm effects. Children's Geographies, 19(3), 317-323.

Novotný, P., Zimová, E., Mazouchová, A., \& Šorgo, A. (2020). Are children actually losing contact with nature, or is it that their experiences differ from those of 120 years ago? Environment and Behavior, 53(9), 931-952.

O'Brien, K., Selboe, E., \& Hayward, B.M. (2018). Exploring youth activism on climate change: Dutiful, disruptive, and dangerous dissent. Ecology and Society, 23(3), 42.

Palmer, J. (1998). Environmental education in the 21st century: Theory, practice, progress and promise. London: Taylor and Francis.

Pickard, S. (2019). Politics, protest and young people: Political participation and dissent in 21st century Britain. London: Palgrave Macmillan.

Pulido, L. (1996). Environmentalism and economic justice: Two Chicano struggles in the Southwest. Tucson: University of Arizona Press

Rousell, D., \& Cutter-Mackenzie-Knowles, A. (2020). A systematic review of climate change education: Giving children and young people a 'voice' and a 'hand' in redressing climate change. Children's Geographies, 18(2), 191-208.

Sandbrook, D. (2020). Why parents are to blame for narcissist youth, says DOMINIC SANDBROOK. Mail Online, 18 July 2020, sec. RightMinds. Retrieved November 19, 2020 from https://www.dailymail.co.uk/debate/article-8535643/Whyparents-blame-age-narcissists-says-Dominic-Sanbrook.html.

Sloam, J. (2020). Young Londoners, sustainability and everyday politics: The framing of environmental issues in a global city. Sustainable Earth, 3(14), 14. 
Solnit, R. (2019). The old made our climate mess. And the young will get us out of it. The Guardian, 11 December 2019 , sec. Opinion. Retrieved November 19, 2020 from https://www.theguardian.com/commentisfree/2019/dec/11/climate-crisisold-v-young-earth-mess.

Tanner, T. (2010). Shifting the narrative: Child-led responses to climate change and disasters in El Salvador and the Philippines: Child-led responses to climate change and disasters. Children and Society, 24(4), 339-351.

Taylor, A. (2013). Reconfiguring the natures of childhood. Abingdon: Routledge.

Taylor, T. (1994). As the old cocks crow, the young ones learn: The school strikes of 1889 and the New Union movement. History of Education, 23(1), 89-106.

Thunberg, G. (2019). No one is too small to make a difference. London: Penguin.

UKSCN. (2020). Justification for strike for schools/colleges (Online). UK Student Climate Network: How to Strike. Retrieved November 23, 2020 from https://docs.google.com/document/d/1BPs6CNgXkpMQohRCh_KhYs1lUFxejqvGjWRRLFJo2BY/ edit.

UNESCO Institute for Statistics (2008). International literacy statistics: A review of concepts, methodology, and current data. Montreal, Canada: UNESCO Institute for Statistics.

Vasudevan, L., \& Campano, G. (2009). The social production of adolescent risk and the promise of adolescent literacies. Review of Research in Education, 33(1), 310-353.

Verlie, B. (2017). Rethinking climate education: Climate as entanglement. Educational Studies, 53(6), 560-572.

Verlie, B., \& Blom, S.M. (2021). Education in a changing climate: Reconceptualising school and classroom climate through the fiery atmos-fears of Australia's Black summer. Children's Geographies, 29(3), 1-15. DOI 10.1080/14733285.2021. 1948504.

Dr Benjamin Bowman is Lecturer in Sociology at Manchester Metropolitan University and a member of the Manchester Centre for Youth Studies. He is an interdisciplinary researcher with an interest in young people's everyday lives, young activism and young people's experiences of climate change.

Dr Chloé Germaine is Senior Lecturer at Manchester Metropolitan University. She writes about and teaches children's literature, culture and young people's climate change imaginaries. Her interdisciplinary research on climate change includes studies of climate fiction and climate change board games, and her previous publications include articles on children's Gothic, Weird fiction, witches and the postcolonial Gothic.

Cite this article: Bowman, B., \& Germaine, C. (2022). Sustaining the old world, or imagining a new one? The transformative literacies of the climate strikes. Australian Journal of Environmental Education 38, 70-84. https://doi.org/10.1017/aee.2022.3 